\title{
Os cus de Judas, de António Lobo Antunes: uma releitura do passado histórico português a partir da desconstrução do "eu"
}

\author{
Eduardo Luiz Baccarin-Costa ${ }^{1}$
}

\begin{abstract}
RESUMO: O presente artigo procura analisar, de maneira sucinta, como o romance Os cus de Judas, de António Lobo Antunes, propôs, por meio da memória, uma releitura do passado histórico de Portugal. A partir deste romance, de acordo com teóricos como Seixo (2006), Reis (2004) e Arnaut (2007), tanto a literatura portuguesa quanto a própria história e especialmente a Guerra Colonial de Angola e a Revolução dos Cravos pôde ser pensada e entendida. Também procuramos mostrar como, sob a perspectiva do narrador, o conflito de identidades entre colonizador e colonizado e as ideologias capitalistas e socialistas fragmentam o narrador-personagem, dando a ele a conotação de romance pósmoderno, como defendido por Hutcheon (1991).
\end{abstract}

PALAVRAS-CHAVE: Os cus de Judas; Memória; Narrador pós-moderno; Novo romance português.

\section{Os cus de Judas (The Land at the end of the world), by António Lobo Antunes: a re- reading of the portuguese historic past from the decline of the individuality}

\begin{abstract}
This article, briefly analyzes how the novel Os cus de Judas (The Land at the End of the World), by António Lobo Antunes, proposed a re-reading to the historical past of Portugal. From this novel, according to theoreticians like Seixo (2006), Reis (2004) and Arnaut (2007), both Portuguese literature and history itself and especially the Colonial War of Angola and the Carnation Revolution could be thought and understood. From the perspective of the narrator, Lobo, I also show how the conflict of identities between colonizer and colonized and capitalist and socialist ideologies fragments the narrator-character, giving it the connotation of a postmodern novel, as advocated by Hutcheon (1991) .
\end{abstract}

KEYWORDS: Os cus of Judas; The Land at the End of the World; Lobo Antunes; Postmodern narrator; New Portuguese novel.

\section{Introdução}

"A Memória só existe ao lado do esquecimento: um complementa e alimenta o outro, um é o fundo sobre o qual o outro se inscreve”, afirma Seligmann- Silva (2003, p. 295). Isso reflete, em parte, a ideia na qual estamos inseridos nestes tempos pós-modernos. Numa sociedade na qual tudo parece imediato e descartável, enfatizar aspectos que digam respeito à memória parece um contraponto e um contrassenso.

Entretanto, urge, em tempos que a democracia e a liberdade conquistada com lágrima,

\footnotetext{
${ }^{1}$ Mestre e Doutorando em Estudos Literários pela Universidade Estadual de Londrina.
} 
suor e vidas parece duramente ameaçada, resgatarmos a memória de um passado relativamente recente: As ditaduras militares que assolaram o mundo - especialmente Portugal e Brasil - na segunda metade do Século XX.

Numa espécie de continuidade do horror vivido com o Holocausto ocorrido na Segunda Guerra Mundial, as ditaduras de Salazar em Portugal e dos Militares no Brasil especialmente nos Governos Costa e Silva e Médici, cujas mãos de ferro" estiveram sobre todos aqueles que ousaram contestar suas ideias conservadoras - produziram o que de pior pode ser manifesto num regime político: $\mathrm{O}$ autoritarismo, a censura, a prisão, o exílio, a tortura, a morte.

Adorno (1998, p. 26) foi categórico ao afirmar, em 1949, que “escrever um poema após Auschwitz é um ato bárbaro", e talvez o filósofo alemão estivesse certo, no sentido de exigir uma pausa na história para uma reflexão profunda da monstruosidade ocorrida naqueles campos de concentração. Não imaginava, porém, que nas casernas espalhadas pelo mundo alguns militares aprovavam os métodos de Adolf Hitler e ainda os poriam, de certa forma, em prática sob a alegação - agora - da manutenção da Ordem e que esta barbárie ainda seria disseminada.

Seligmann-Silva (2003), trata a leitura do 'passado' como uma escritura que só se deixa perceber num determinado 'agora', e de certa forma ela está relacionada, também ao conceito de pós-modernidade, pois se tem logo a ideia de que tal período se desenrolou a partir de eventos traumáticos, como as duas grandes guerras e as ditaduras que assolaram o mundo no século XX. Tais eventos provocaram uma nova e profunda ruptura nos padrões e nos conceitos estéticos das artes. Dentre estas, a literatura. Assim, lembra Franco (2003, p. 323), a literatura como arte deve "ser considerada uma espécie de resistência e compreende uma dimensão ética, enquanto manifestação de indignação radical diante do horror". E somente revisando a história poderemos redimir a própria humanidade.

Massaud Moisés (2005, p.40) ao ampliar o conceito de literatura e da própria função social, política e literária do narrador defende que "fazer literatura é criar uma pararrealidade, um universo paralelo que só ganhará existência a partir da relação entre uma virtualidade geradora (o texto) e uma entidade captadora (o leitor)", ou como enfatiza Joaquim Ferreira dos Santos (2005, p.15) na introdução da sua coletânea As cem melhores crônicas brasileiras, "Literatura é tudo aquilo que permanece".

Entre as formas nas quais a literatura encontra o poder de eternidade está o resgate ou a releitura de fatos históricos. Redimensionar a própria história por meio da memória é uma das funções sociais da literatura e uma característica do novo romance histórico contemporâneo. 
Especialmente a partir da segunda metade do século XX, quando ditaduras de direita e esquerda grassaram pelo mundo, a forma de resistência encontrada pela literatura foi a de enunciar um devir usando metaforicamente o poder da memória. E na adoção de tal procedimento se enquadrou o que ficou conhecido como Testimonio, ou mais tarde denominada Literatura de Testemunho.

O conceito de testimonio, já vigente na literatura de língua espanhola desde o início do século XX, teve na década de 1960 uma ampliação deste escopo, voltando-se especialmente para os relatos - ainda que fictícios - dos sobreviventes das atrocidades ocorridas nas ditaduras que se alastraram por todo o mundo. Nesta ampliação, foi incorporado o que Seligman-Silva (2003, p. 32) chama de "política da memória", o que permite uma convergência expressiva entre política e literatura, tornando-se assim o gênero "mais apto para 'representar os esforços revolucionários dos oprimidos".

O testemunho é para autores como Márcio Selligman-Silva (1999 e 2004) e Malcolm Silverman (1995) uma espécie não só de rememoração de um luto, como um rito de passagem desse luto para a retomada da vida, após períodos traumáticos. Assim, a memória auxilia não só o resgaste do passado, como também propicia por meio do registro testemunhal um efeito catártico das emoções que auxiliam no processo de superação do luto.

O recurso estético da memória como um combate das diferentes vozes da narração do passado, e a partir daí, uma reestruturação do presente, não deve ser visto exclusivamente como um dos pilares de sustentação da Teoria da Memória, insiste Selligman- Silva (2003, p. 37). Até porque não se deve considerar o testemunho uma simples "manifestação do 'pós-literário, mas sim a afirmação da resistência do literário, e resistir é uma das funções sociais da literatura". Ou como afirma Roney Cytrynowicz:

é preciso que cada documento da barbárie seja recuperado, estudado, criticado, entendido, conservado, arquivado, publicado e exposto, de forma a tornar a história numa forma presente de resistência e de registro digno dos mortos, muitos sem nome conhecido e sem túmulo (CYTRYNOWICZ, 2003, p. 126).

Cytrynowicz, neste excerto, refere-se exclusivamente à literatura que trata dos eventos ligados aos horrores vividos pelos judeus entre 1939-1945, na Polônia. Porém, tomando como referencial o pensamento de Franco (2003), para quem as ditaduras latino-americanas dialogam diretamente com Auschwitz, no que diz respeito à tortura e morte e, levando em consideração o histórico da literatura produzida nos anos 1960-1970, no Brasil, esta deve ser sim considerada, respeitando as condições de produção de cada momento, como um resgate da História. 


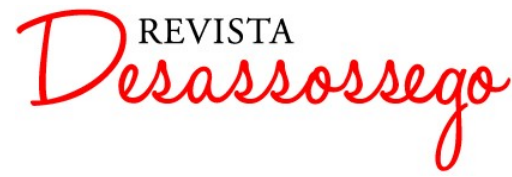

DESASSOSSEGO 20 - parte 2 |JUN/2019 | ISSN 2175-3180

DOI: http://dx.doi.org/10.11606/issn.2175-3180.v11i20p210-223

Benjamin (1993, p. 221) afirma que "o narrador é a figura na qual o justo se encontra consigo mesmo". Esse encontro, no caso específico de autores que produziram romances cujo tempo de enunciação é o período de ditaduras, e a opção estética é pelo memorialismo, é a forma como ele, de acordo com Seligmann-Silva (2004), expia sua condição de sobrevivente, relatando as angústias de um tempo no qual o horror e o silenciamento eram comuns.

Lobo Antunes conseguiu, em Portugal, por meio das suas reminiscências, fazer com que a memória fosse um instrumento significativo de engajamento político e literário. Em que pese seu intenso debate com José Saramago sobre suas posturas ideológicas e narrativas, o autor de Os cus de Judas impôs seu nome no panteão dos grandes escritores portugueses contemporâneos, basicamente falando de si.

Fazer da escrita não só uma forma de testemunho, mas uma forma de se relacionar mais presentemente com um passado, procurando ressignificá-lo e entendê-lo ou, nas palavras de Barthes (2004, p. 208) “ [...] relacionar todo o referente («O que se diz») a este ato de locução” é o que faz o narrador de Os cus de Judas, de António Lobo Antunes.

Assim, o presente trabalho pretende estudar o recurso do falar de si como resgate da memória e como evidenciação do conflito de identidades no discurso do narrador de Os cus de Judas. Também pretendemos analisar, ainda que sucintamente, como essa desconstrução desse eu, essa fragmentação e os assujeitamentos revelados por este narrador configuram o romance de António Lobo Antunes, não só como um romance pós-moderno, mas como uma metaficção histórica, como define Hutcheon (1991), características do novo romance histórico da pós-modernidade.

\section{OS CUS DE JUDAS - A MEMÓRIA COMO INSTRUMENTO DE RELEITURA DO PASSADO DO NARRADOR}

António Lobo Antunes é um dos principais nomes da literatura contemporânea portuguesa, tendo inclusive norteado um trabalho de Maria Alzira Seixo, renomada ensaísta lusitana, professora e estudiosa da Literatura Portuguesa: o Dicionário para ler a obra de Lobo Antunes (2006).

Psiquiatra de formação, Lobo Antunes, como quase todo jovem que cresceu em meio à ditadura Salazarista, foi obrigado a servir ao Exército Português na Guerra de Libertação de Angola. No caso específico do autor português, ele esteve no campo de batalha, atuando como médico, nos anos finais, mais especificamente entre 1971 e 1973.

A ida de Lobo Antunes para a Guerra de Libertação de Angola foi decisiva para a primeira fase da obra do autor, aponta Costa (2013) em sua Tese de Doutorado, "Para um 
estudo da memória e identidade portuguesas com António Lobo Antunes”. Na África nasceu a "poética do retorno", conjunto de seus primeiros romances, publicados a partir de 1979: Memória de elefante, Os cus de Judas e Conhecimento do inferno. Com essa trilogia, Lobo Antunes usa das memórias e das reminiscências para revelar a angústia de quem viveu a experiência traumática de um campo de batalha.

Em Portugal, parte significativa do século XX foi vivido sob o signo da ditadura e do silenciamento. Lá, Salazar, e posteriormente, Marcelo Caetano, conduziram por quase meio século o estado com mão de ferro, tentando manter vivas as ideias do reino lusitano das conquistas ultramarinas. Seu projeto de fazer de Portugal uma grande nação europeia passava pela manutenção das colônias além-mar, subtraindo delas todo o tipo de riqueza. Muitos jovens portugueses encontraram a morte ou a invalidez permanente tentando defender a ideologia do ditador português. É neste ponto - o desaparecimento trágico de tantos jovens - que reside a essência da trilogia inicial da produção literária de Lobo Antunes, o que possibilita uma leitura crítica da história lusitana no Século XX.

Estudiosos da Literatura Portuguesa e especialmente da obra de Lobo Antunes, como Ana Paula Arnaut e Maria Alzira Seixo, são enfáticos em afirmar como seus romances ajudaram a entender a história recente portuguesa. Mesmo publicando após o período mais traumático para o povo português no século XX - a ditadura de Salazar -, os romances de Lobo Antunes mostram como a população assistiu passivamente aos absurdos daquele governo, especialmente ao envio dos jovens para as guerras das colônias de Moçambique e Angola. Lobo Antunes se enquadra perfeitamente naqueles escritores que melhor proporcionaram à literatura uma leitura crítica do passado português.

O romance de Lobo Antunes desde sua primeira publicação foi muito bem acolhido pela crítica e por vários setores da Academia. Uma das razões apontadas para o acolhimento da obra está no fato de ser notória, no romance português contemporâneo, a importância da memória como reescrita dos fatos históricos (Seixo, 2006). O diferencial é que o romance se encaixa no conceito de literatura feita a partir da memória, mas não se limitando à referência pretérita, e sim apontando para a realidade na qual foi produzida. Com isso, mostra a postura crítica dos autores perante as mazelas políticas e sociais em que vivem, revelando as mais profundas contradições da condição humana. No caso específico de Lobo Antunes, a história passa a ser uma motivação pretextual para a transfiguração da pessoa humana.

A trilogia denominada por Lobo Antunes como "Poética do Retorno" tem em Os cus de Judas o ponto máximo da agonia de um sujeito que conta, descreve, julga e fantasia, permitindo assim uma "polarização binária entre passado e presente, infância mítica e juventude 
desenganada, conforto amoroso e solidão singularizante". Seixo ressalta também a presença das metáforas, das recordações (evocações) e da narração conjectural como recursos diegéticos, e a presença da polarização ideológica significada pela “[...] crítica ao fascismo, absurdo da guerra e aberração histórica do colonialismo, responsabilidade humana política e cívica, sentido da existência e condicionamentos classistas, dimensão moral do poder” (SEIXO, 2006, p. 38).

Para entender melhor a análise da autora, é importante frisar que em Memória de elefante, as reminiscências do menino que andava pelas ruas de Lisboa, seus laços familiares, sua paixão pelo Benfica, time de futebol português, e a mudança que o país experimentou no século XX, especialmente com a ditadura de Salazar, estão presentes. Em Conhecimento do inferno, o narrador é um jovem profundamente traumatizado pela Guerra que, em viagem para o litoral português expõe suas lembranças daquele tempo, fazendo com que a enunciação do romance - no presente - revele os horrores experienciados em constantes flashbacks da memória do narrador.

Porém, ressalta Vale (2014, p. 151) é com Os cus de Judas que a obra de Lobo Antunes se torna mais engajada, crítica, reflexiva. A autora lembra que especialmente com estas três obras, a narrativa antuniana irá descrever o mundo interior da "casa portuguesa", mundo este em ruínas, uma vez que toma consciência das práticas de controle do regime sobre os sujeitos, em parte referendadas pela "casa" da qual é herdeiro: "São romances que espelham a transição vivida não só pelo autor, mas por Portugal como um todo".

No romance de Lobo Antunes, tem-se um procedimento narrativo que revela tal transição resultando, por isso, num fluxo de consciência desordenado, fragmentado. A memória funciona como num processo analítico da sua própria vida. Quando o narrador salienta que é na própria morte que se teme a vida alheia ou que é "a tropa há de torná-lo um homem" (Antunes, 2003, p. 23), o processo crítico já é estabelecido, logo nas páginas iniciais do romance. A mudança radical de uma vida tranquila em Lisboa para a liberdade solapada por um governo que vendia a imagem de um novo império português enquanto roubava todas as liberdades do cidadão, são “fantasmas vivos" presentes nos longos monólogos interiores de Os cus de Judas.

Costa (2013, p. 89) salienta que a obra de Lobo Antunes proporciona uma leitura bastante privilegiada dos fatos recentes envolvendo a história de Portugal, especialmente os eventos que irão proporcionar a Revolução dos Cravos em 25 de abril de 1974. Para ele, “[...] ao apresentar toda uma série de vetores que, para além de permitirem uma compreensão mais aprofundada da real evolução da imagem nacional portuguesa, acarretam a possibilidade de identificação das estratégias que para esta concorrem". 
Em Os cus de Judas, o narrador-personagem enuncia, ao longo dos 23 capítulos - com os sugestivos nomes das letras do alfabeto de A a Z, uma espécie de dilaceramento do enunciador, como refere Seixo (2006). Além dessa fragmentação, o romance revela um choque de identidades entre lusitanos e africanos que ficou evidenciado, neste período, fosse pelos recursos bélicos, fosse por suas visões de mundo, de paixão, de sexo. Essa postura verificada pelo narrador reforça o pensamento de Hall (2006, p.102) para quem "as identidades são, pois, pontos de apego temporário às posições-de-sujeito que as práticas discursivas constroem para nós".

Em outros momentos, o narrador-personagem distancia desse caráter epistolográfico e usa de Sofia, sua ouvinte convertida em interlocutora para, por meio de longos monólogos interiores, estabelecer uma relação dialógica com o leitor, a quem relata todas as suas angústias pessoais e políticas. Nesse fluxo de memória, multiplicam-se tempos e espaços narrativos. Estes, não estão "limitados nem circunscritos com precisão, mas apresenta, porém, traços vincados, que se repetem de modo incisivo, a figurarem não tanto uma inalterabilidade das coisas como o poder da memória que os captou” (SEIXO, 2010, p. 78).

Dessa maneira, a estratégia de utilizar a memória como fio condutor de suas narrativas revela muito mais a natureza traumática desse eu que enuncia suas angústias do que precisamente a sua necessidade de recordar. Quando a memória está de alguma forma ligada à paixão e à ideologia, a pertinência de suas reminiscências pode ampliar a sua noção de trauma (Fonseca, 2015). Por isso a obra de Lobo Antunes proporciona uma visão bastante consistente do Portugal salazarista e dos primeiros anos após a Revolução dos Cravos, uma vez que a Guerra de Angola só terminaria depois do fim da ditadura.

Tal estratégia está calcada nos microdiscursos enunciados pelo narrador-personagem em oposição ao macrodiscurso do governo de Salazar que queria, entre outras coisas, ressuscitar o mito do sebastianismo, fazendo do povo lusitano novamente uma nação dominadora e colonizadora do mundo. Isto nos faz levantar a hipótese de que Os cus de Judas, por meio de seus procedimentos, se enquadre ou, no mínimo, se aproxime do conceito de romance histórico pós-moderno, ou seja, romance que revela um homem fragmentado, em conflito com suas identidades, longe das subjetividades do romance realista, mas muito centrado num eu em processo de construção contínua..

Essa aproximação, no caso específico de Os cus de Judas, se dá pelo recurso da memória e da reminiscência, apontadas por Benjamin (1993), por meio do narrador-personagem. Ao lidar com os conflitos históricos, com os conflitos identitários entre europeus e africanos, colonizador e colonizado, ao fazer um retrato crítico e histórico do povo português, o narrador 
do romance, de maneira quase explícita, dialoga diretamente com fatos históricos, estabelecendo alguns intertextos e interdiscursos que permitem uma releitura crítica de fatos ocorridos. Afinal, “ [...] os romances não são escritos para contar a vida, mas transformá-la após o processo de leitura." (ESTEVES, 2010, p. 43).

No romance de Lobo Antunes, a transformação do processo histórico acontece simultaneamente à transformação do narrador-personagem e induz a um processo semelhante por parte do leitor. Publicado em 1979, portanto quatro anos após a Revolução dos Cravos e quase cinco da experiência vivida pelo autor, a guerra colonial era uma ocorrência de um presente distante, um movimento em outro continente e, no registro oficial, era assim registrada. Isso aconteceu, também, porque só a partir de 25 de abril de 1974, segundo Álvaro Manuel Machado (1984) é que o país pôde se contemplar “[...] no espelho imaginário da sua própria história ", por meio especialmente das artes e da literatura. Essa é, para ele, "[...uma procura essencial da identidade". (MACHADO, 1984, p. 103). Antes, porém a Literatura ficou estanque em terras lusitanas, "parada no tempo", de acordo com Machado (1984) e Mourão (1996). Para se ter uma ideia, em Portugal, por exemplo, chegou-se a criar um index de livros e autores "malditos" que sequer poderiam ser mencionados.

Dessa maneira, ao trazer esse presente distante como presente da enunciação, Lobo Antunes vivifica o tempo experienciado, ampliando a historicidade do fato. O caráter autobiográfico não é condicionado por um tom inovador, mas sim por uma reformulação do sujeito social, que constrói uma memória pela agregação de um espaço maior. Por meio do procedimento autorreferencial adotado, Lobo Antunes dialoga diretamente com seu leitor, convertido num narratário, e dá ao conjunto destas obras, produzidas no final dos anos 1970 e início dos anos 1980, especialmente a marca de "obras sem a prolixidade de vozes e de pontos de vista, que caracterizarão, progressivamente, as obras dos ciclos posteriores" (ARNAUT, 2009, p. 32).

Fernandes $(2009$, p. 3) ressalta que, em linhas gerais, dois momentos históricos são os escolhidos como tempo de enunciação dos romances antunianos: a Guerra de Angola e a Revolução dos Cravos. Usando a memória como condutor, Lobo Antunes usa de procedimentos em que há “ [...] alternações no enfoque narrativo e imprecisões; descrições pormenorizadas e estruturas metalépticas; e há a busca das personagens-narradoras por expressar e expurgar tudo o que viram e sentiram."

Navas (2012, p.13) sustenta que na narrativa de Lobo Antunes, constantemente remissiva e afetiva, tem-se uma "escrita que se suspende, se interrompe e se retoma, cruzada de falas distintas, vindas de dentro e fora do texto, entrelaçando-se em um xadrez de alusões, 
variações e repetições, como se tudo e todos falassem ao mesmo tempo e, assim, enredam" o leitor, numa espécie de catarse que causa um misto de estranhamento e identificação.

Tais ativações ocorrem, segundo Costa (2015, p. 90), muito provavelmente em decorrência de que " quem narra se confunde em diversas situações com a da própria personagem que comanda o percurso diegético,” o que permitirá uma apreensão do leitor de que está diante de uma obra na qual se tem “ um hipotético cenário de desajustamento social por parte de um determinado indivíduo, que busca a todo o custo a sua reintegração no plano comunitário original". E as memórias do narrador-personagem em Os cus de Judas, especificamente, são permeadas pelas lembranças do passado e expectativas em relação ao futuro, ancoradas nas suas lembranças pessoais, nos seus frustrados relacionamentos afetivos inclusive de uma paternidade vivida à distância.

Os cus de Judas são o resultado de uma "aprendizagem da agonia” (Antunes, 2003, p. 23) que se deu ao longo da vida do narrador. A angústia deste ganha corpo em sua fala e, em meio ao conflito de saber quem verdadeiramente é, tenta se reconstituir enquanto dialoga com sua interlocutora. No entanto, a imagem que se apresenta aos leitores é de um eu cindido, de um eu dividido entre o que ele era, o que os outros atores sociais e as instituições esperavam que ele fosse, aquilo no que ele se tornou e o que ele gostaria de ser.

Consequentemente, não há uma consonância na definição identitária desse indivíduo, até mesmo porque é justamente a partir "do ruído social, dos conflitos entre os diferentes agentes e lugares de socialização" que esse "eu" se constrói. Logo, suas identidades são "relacionais e múltiplas, baseadas no reconhecimento por outros atores sociais e na diferenciação, assumindo na interação um papel crucial neste processo". (MENDES, 2002, p. $505)$.

Fonseca (2015, p. 90) denomina a narrativa presente em Os cus de Judas como um exemplo da " memória corporal, com a ênfase dada à dimensão sensorial, na interação que se estabelece entre corpos, espaços e objetos" e acrescenta que isto " [...] é fundamental e apresenta uma forte relação com os lugares.” Nestes lugares são revelados os contrastes e os conflitos identitários e pessoais que permeiam o romance. Assim tem-se o bar, o caminho para casa, o hospital, a casa do narrador contrapondo-se, nos "diálogos" enunciados, com a casa da infância, as cozinhas, a escola, o zoológico, e as cidades portuguesas de onde vieram os jovens para lutar e morrer em Angola.

Importante ressaltar que Lobo Antunes não poupa críticas ao governo Salazarista, não só pela Guerra Colonial, como também pela ditadura que assolava Portugal desde 1926. Ao usar a imaginação, o narrador está também fazendo duras críticas não só ao governo instituído, 
como às entidades que mantêm esse sistema. Nesse sentido, a família tradicional portuguesa teve papel fundamental. Por isso, Oliveira (2004, p.14) ressalta que em Os cus de Judas "a família e o Estado têm no romance uma função comum: ambos atuam como repressores do sujeito. São instituições avessas ao prazer, à felicidade, esterilizadoras das potencialidades do indivíduo". Isso pode ser comprovado no seguinte trecho:

[...] pertenço à dolorosa classe dos inquietos tristes, eternamente à espera de uma explosão ou de um milagre, qualquer coisa de tão abstrato e estranho como a inocência, a justiça, a honra, conceitos grandiloquentes, profundos e afinal vazios que a família, a escola, a catequese e o estado me haviam solenemente impingido para melhor me domarem, para extinguirem, se assim me posso exprimir, no ovo, meus desejos de protesto e revolta (ANTUNES, 2003, p.122).

Ao longo de toda a narrativa, como é o caso do exemplo acima, o procedimento narrativo adotado por Lobo Antunes, por meio desse fluxo de consciência constante, revela a experiência vivida em Angola. Ao adotar essa autodiegese, de certa forma, faz uma aproximação das narrativas testemunhais que procuram, por meio de uma enunciação no presente, encontrar explicações plausíveis para um passado que atormenta. Esse recurso é característico da metaficção historiográfica preconizada por Hutcheon (1991, p.39) e traço marcante do pósmodernismo. Para a autora, “ o pós-modernismo não nega a existência de um passado, mas de fato questiona se poderemos conhecer o passado a não ser por meio de seus restos textualizados". Por este viés, a narrativa do "eu" talvez tenha sido o procedimento mais utilizado para unir estes restos. Esse narrador fragmentado é aquele que, dentro da perspectiva benjaminiana, faz uma simbiose da sua própria experiência amalgamada com a alheia, para dar mais veracidade à narrativa enunciada. Assim, o narrador de Os cus de Judas organiza seu enredo a partir das próprias experiências, recorrendo à memória e descrevendo minuciosamente os fatos numa perspectiva subjetiva.

O narrador de Os cus de Judas sugere que a vida real e a guerra também não são lineares, assim como seu fluxo de pensamento. Dessa maneira, cabe a ele "a tarefa de traçar sua precária trajetória com o auxílio do ir e vir da memória associando, inclusive, cheiros, imagens e fatos de sua fase adulta à sua infância". Mesmo sendo uma narrativa autobiográfica, o narrador faz o jogo de tensão dialógica com o leitor, enunciando "uma seleção de imagens de si mesmo que deseja projetar por meio de um "eu" simulado. Logo, identificamos a construção de um sujeito ficcional, cuja intimidade é dada como um espetáculo bárbaro" (FONSECA, 2015, p.145).

A partir do capitulo S, o narrador retoma seu contato com Sofia. A interlocutora antes imaginária agora ganha nome e função: era lavadeira de Gago Coutinho e torna-se amante do 
narrador. A presença dela imprime um tom mais dialógico à narrativa, sem no entanto, haver uma prevalência de um personagem em relação ao outro. Ocorre aqui o dialogismo a que Bakthin (1988) se refere, pois as vozes de narrador e personagem se equivalem completamente.

Fica a impressão, assim, que ao falar de si, as múltiplas vozes que emergem em Os cus de Judas aparecem como elemento intrínseco do narrador. Os poucos momentos em que a diegese é evidenciada, transformam-se rapidamente em mónologo interior, o que confere nesta narrativa autobiográfica, ao contrário de boa parte deste tipo de narrativa, o caráter dialógico a que Bakthin se refere.

O recurso da escrita de si para enunciar no presente o trauma do passado, possibilita ao narrador de Os cus de Judas um desnudamento de suas falhas e feridas, ainda que abertas, como quem deseja denunciar a sua fragmentação diretamente relacionada ao meio em que ele viveu. Além disto, ressalta Silva (2012), ao extravasar suas angústias e dividir o ônus da guerra com o leitor, convertido em interlocutor, provoca-o a participar dos eventos narrados, questionando sua identidade e a identidade de Portugal, mergulhada então numa longa ditadura.

O declínio de um “eu” em Os cus de Judas está diretamente ligado à acentuada desintegração que o narrador-personagem vai, paulatinamente, sofrendo, conforme as inquietações, a distância, a consciência política e histórica vão florescendo ao longo do romance. Tais características são marcas que comumente ganham forma nas manifestações artísticas, elaboradas a partir da segunda metade do século XX.

Teóricos como Jameson (1997) e Hutcheon (1991, p. 20) apontam a pós-modernidade, e o próprio conceito polêmico de pós-moderno, como "fundamentalmente contraditório, deliberadamente histórico e inevitavelmente político". Em Os cus de Judas, tais características se acentuam nesse declínio do narrador que assiste ao seu "aprendizado da agonia", num misto de sentimentos que aludem à sua desintegração, que passa a ser representado a partir de um cenário confuso, perturbador, que detêm uma amostra de nossa mentalidade.

No entanto, a dor e a agonia do narrador-personagem parecem não se esgotar nos monólogos interiores ou nos diálogos com um interlocutor distante, ausente. A cada capítulo, caprichosamente divido de A a Z, como se mostrasse o alfabetizado da aprendizagem dolorosa e do amadurecimento forçado, os sentimentos enunciados dão a mesma impressão dos sobreviventes do holocausto. E isto corrobora o que defendem Franco (1998), Selligman-Silva (2003) e Silverman (1995), de que as ditaduras e as guerras, para sua manutenção, se assemelham ao trauma vivido nos campos de concentração.

A inquietação, o senso crítico e a consciência política reveladas no calor da guerra fazem deste narrador-personagem leitor privilegiado das semiologias da história. Ao contrapor suas 
lições da escola com a realidade experenciada, passa a fazer da memória fio condutor de sua narrativa, o que o transforma num "contador de histórias". Os livros e os retratos da parede, que estabelecem um referente em relação aos atravessamentos ideológicos experimentados pelo narrador, parecem estabelecer um filtro subjetivo. Assim, o procedimento estético com base nas memórias passa a ser uma espécie de ethos discursivo cuja finalidade seria a de revelar essa identidade.

\section{Considerações Finais}

O narrador de Os cus de Judas revela por meio de sua narrativa, como salienta Silva (2012), não só o espanto e a indignação por confrontar seus valores, como revela sua profunda perplexidade de quem vivenciou a guerra, enfim, do incomensurável. $\mathrm{Na}$ escrita, aflora o inesquecível que, agora, passado o tempo, assume uma forma transmissível.

Benjamin (1993) considera o narrador um contador de histórias, alguém que repassa por meio da narrativa romanesca a própria história, redimensionando-a. Para Bakthin (1998), a memória é a força criadora que dá impulso ao romance do século XX. Isto é o que Lobo Antunes faz com mestria em Os cus de Judas: a partir de suas memórias, transpõe suas angústias e suas inquietações, dilacerando o aprendizado da agonia a qual foi submetido - tanto como autor como narrador - e expondo as mais variadas fragmentações pelas quais ambos foram expostos.

O narrador em Os cus de Judas possibilita uma revisão da história recente portuguesa, especialmente da Guerra Colonial de Angola. As angústias enunciadas neste "aprendizado de agonia" acabam por revelar como as ideias obsessivas de um ditador em resgatar um passado glorioso - colonizador - que já não faziam mais sentido, levou milhares de jovens à morte ou à invalidez permanente, para defender uma causa que, sinceramente, não acreditavam.

Todos os efeitos colaterais que qualquer guerra produz - solidão, angústia, morte, delírio - são retratados de forma poética, num relato autobiográfico pungente, mas que não deixa de ser crítico e reflexivo. Pensar a morte como uma dicotomia constante com a vida é um dos recursos que a narrativa nos proporciona, pois enquanto ele tem a morte como uma companheira constante nos “cus de judas", em Portugal sua filha vive seus primeiros dias. Neste embate ele nunca sabe qual das duas o abraçará primeiro.

Com estas angústias, acabam também vindo à tona às questões de identidade. $\mathrm{E}$ tais questões revelam um narrador fragmentado - assim como colonizador e colonizado - que buscando se autofirmar têm de lidar com a alteridade. Tem-se aqui um caminho aberto para 
novas e mais profundas reflexões que Os cus de Judas pode nos proprocionar: os meandros de como a memória e as relações fluidas fazem-nos perceber o outro em nós mesmos. Talvez seja essa a grande lição que a narrativa de Lobo Antunes nos proporciona: apreender como, em momentos de agonia e questionamentos profundos, podemos deixar vir à luz nossos melhores e piores sentimentos, moldando melhor nossa identidade e respeitando melhor o espaço - físico e geográfico - alheio.

\section{Referências:}

ADORNO, Theodor W. Prismas: critica cultural e sociedade. Tradução: Augustin Wernet e Jorge Mattos Brito de Almeida. São Paulo: Ática, 1998.

ANTUNES, Antonio Lobo. Os cus de Judas. Rio de Janeiro: Objetiva, 2003.

BAKHTIN, Mikhail. Questões de literatura e estética: a teoria do romance. Tradução: Paulo Rónai. São Paulo: Hucitec, 1988.

BARTHES, Roland. A morte do autor, in: O rumor da lingua. Tradução: Sérgio Luiz Barros. Lisboa, Portugal: Edições 70, 6 ed. 2004.

BENJAMIN, Walter. Magia e técnica, arte e política: ensaios sobre a literatura e história da Cultura. Trad.: Sérgio Paulo Rouanet. 5 ed. São Paulo: Brasiliense, 1993.

COSTA, Jorge M. A. G. Para um estudo da memória e identidade portuguesas com António Lobo Antunes. Universidade Católica Portuguesa: Beiras, Portugal. 2013.

CYTRYNOWICZ, Roney. O silêncio do sobrevivente: diálogo e rupturas entre memória e história do holocausto, in SELIGMANN-SILVA, Márcio (org.). História, memória, literatura: o Testemunho na Era das Catástrofes. Campinas-SP: Editora da Unicamp, 2003. p. 103-128.

FONSECA, Carlos Henrique. Tempo, memória e identidade em Os cus de Judas de António Lobo Antunes. Araraquara-SP: Unesp, 2015

FRANCO, Renato. Itinerário Político do Romance Pós-64: A festa. São Paulo: Fundação Editora da Unesp, 1998.

HUTCHEON, Linda. Poética do Pós-Modernismo. Tradução Ricardo Cruz. Rio de Janeiro: Imago, 1991.

JAMESON, Frederic. Pós-modernismo: a lógica cultural do capitalismo tardio. Tradução Maria Elisa Cevasco. São Paulo: Ática, 1997.

MOISÉS, Massaud. A criação literária: poesia, 17 ed. São Paulo, 2005.

SANTOS, Joaquim F. (org). As cem melhores crônicas brasileiras. Rio de Janeiro: Objetiva, 2005.

SEIXO, Maria Alzira. Dicionário da obra de António Lobo Antunes. Lisboa: Imprensa Nacional - 
Casa da Moeda, 2006.

SEIXO, Maria Alzira. Os romances de António Lobo Antunes: análise, interpretação, resumos e guias de leitura. Lisboa: Dom Quixote, 2010

SELIGMANN-SILVA, Márcio (org.). História, memória, literatura: o testemunbo na era das catástrofes. Campinas: Editora da Unicamp, 2003.

SILVA, Ana Paula. "Aprendizagem da agonia" em Os cus de Judas, de António Lobo Antunes. UFVUniversidade Federal de Viçosa. Viçosa-MG, 2012

SILVA, Ana Paula. Repensando o campo literário a partir do testemunho: um percurso de Ésquilo a Lobo Antunes. In: DUARTE, Leila Pereira (Org.). A escrita da finitude: de Orfeu e de Perséfone. Belo Horizonte: Veredas e Cenários, 2009.

SILVERMAN, Malcolm. Protesto e o novo romance brasileiro. Porto Alegre: Ed. da Universidade UFRGS, 1995.

VALE, Glaura S.C. A escrita como resistência em António Lobo Antunes. Revista Em Tese, vol. 20, n. 2, p.150-170. Belo Horizonte, 2014. Disponível em < http://www.periodicos.letras.ufmg.br/index.php/emtese/issue/view/303>, acesso em $31 / 03 / 2018$. 